\title{
LONG-DISTANCE RUNNING AND ITS EFFECTS ON CARDIORESPIRATORY ADAPTATION AND PHYSIOLOGICAL STRAIN IN MARATHON RUNNERS
}

\author{
Katarzyna Przybyła, ${ }^{\mathrm{B}, \mathrm{C}}$ Aleksandra Żebrowska, ${ }^{\mathrm{A}, \mathrm{D}, \mathrm{E}}$ Anna Posmysz, ${ }^{\mathrm{B}}$ Beata Manowska, ${ }^{\mathrm{B}}$ \\ llona Pokora, ${ }^{\mathrm{D}}$ Agata Żak ${ }^{\mathrm{B}}$
}

Department of Physiological and Medical Sciences, The Jerzy Kukuczka Academy of Physical Education, Katowice, Poland

A Study Design; ${ }^{\mathrm{B}}$ Data Collection; ${ }^{\mathrm{C}}$ Statistical Analysis; ${ }^{\mathrm{D}}$ Manuscript Preparation; ${ }^{\mathrm{E}}$ Funds Collection

\author{
Address for correspondence: \\ Aleksandra Żebrowska, Ph.D. \\ Academy of Physical Education, Department of Physiology \\ Mikolowska st. 72A, 40-065 Katowice, Poland \\ E-mail: a.zebrowska@awf.katowice.pl
}

\begin{abstract}
Ahstract. Popularity of long-distance running has increased as well as number of female and male marathon runners. Whilst research into physiological characteristics of endurance trained athletes has significantly increased there are only few studies on the risk factors for respiratory failure in marathon runners. Therefore, the aim of the study was to evaluate the differences in respiratory function and the physiological strain in the response to exercise stress in marathon runners. Twenty three subjects (aged $36.1 \pm 11.6$ years) participated in a marathon running. Prior to the run and after its completion, body mass and composition, spirometry and body temperature were measured. Based on pre- and post-run temperature and changes in heart rate, the physiological strain index (PSI) was calculated.

Long-distance running significantly decreased the temperature of body surfaces $(p<0.05)$; no significant effects were observed regarding aural canal temperature and physiological strain index (PSI). Compared to resting values, post-marathon spirometry revealed a significant decrease in post-marathon forced expiratory volume $(p<0.05)$, peak expiratory flow $(p<0.05)$ and maximal expiratory flow values $(p<0.05)$. In conclusion, the long-distance running results in functional changes within the respiratory system which may limit the adaptive potential and decrease exercise tolerance.
\end{abstract}

Key Worlds: marathon, spirometry, physiological strain index

\section{Introduction}

Functional adaptations of the respiratory system during endurance exercise is important for increased gas exchange in the lungs. Balance between muscle oxygen uptake $\left(\mathrm{VO}_{2}\right)$ and carbon dioxide removal $\left(\mathrm{VCO}_{2}\right)$ depends on the adaptation of alveolar ventilation to lung perfusion as well as on changes in blood flow distribution. It has been shown that a decrease in physical performance of long-distance runners might be related to the limitation of respiratory tract adaptive capacity, an increase in physiological strain including the cardiovascular system and thermoregulatory processes (Vogiatzis et al., 2007; Hölmich et al., 1998). 
The results of previous investigations emphasize the role of the respiratory system as well as nervous and hormonal mechanisms in the regulation of local blood flow and, consequently, in the reduction of oxygen transport to the locomotor muscles. In long-lasting physical activity, arterial $\mathrm{O}_{2}$ content $\left(\mathrm{CaO}_{2}\right)$ and/or lower extremity blood flow $\left(Q_{L}\right)$ may reduce competitor's aerobic capacity (Amann, 2012; Moran et al., 1998). Reduction in arterial oxygen saturation $\left(\mathrm{SaO}_{2}\right)$ observed during strenuous exercise can be associated or non-associated with the function of the respiratory system. If it is, metabolic factors and thermal stress play a significant role. Arterial hypoxemia induced by decreased oxygen diffusion and a decrease in cardiac output (CO) resulting from increases in intrathoracic pressure are considered mechanisms associated with respiratory system function during long-lasting endurance exercise (Peters, Bateman, 1983; Neilan et al., 2006). Additionally, increased energy expenditure required by the respiratory muscles during exercise causes stimulation of metabolic receptors, which - due to adrenergic stimulation - decreases the peripheral blood flow. A lot of indices have been proposed to determine physiological strain accompanying muscular activity. Moran et al. (1998) suggested that the Physiological Strain Index (PSI) which reflects the combined burden on the thermoregulatory and cardiovascular systems may be important factor in determining the physiological responses and overreaching symptoms in athletes.

Long-distance running become a more and more popular sport discipline; marathons and ultra-marathons attract an increasing number of participants. Hence, a number of investigations have been undertaken to determine physiological responses and risk factors for health problems in marathon runners (Predel, 2014; Zilinski et al., 2015).

In the light of the above-mentioned observations it seems important to examine differences in respiratory function and the physiological strain during the marathon running.

\section{Material and methods}

The study comprised 23 individuals ( 8 women and 15 men) aged $36.1 \pm 11.6$ years who participated in the VII Marathon Festival organized in autumn 2014 by the Jerzy Kukuczka Academy of Physical Education in Katowice. The inclusion criteria were satisfactory results of the physical examination, participation in at least two marathons and written consent to take part in the study. During the run and immediately after finishing, the participants were under medical supervision. The study protocol was approved by the Ethics Committee of the Academy of Physical Education in Katowice, Poland, and conformed to the ethical standards (Kruk, 2013).

Prior to the run and after its completion, body mass and composition of all participants were estimated using bioelectrical impedance analysis (Tanita BC-418MA Analyzer). Body height was measured and fat mass (FAT), fat-free mass (FFM), total body water (TBW) and body mass index (BMI) were calculated. The study subjects' data are presented in Table 1.

All participants underwent spirometry testing to determine vital capacity (VC), forced vital capacity (FVC), and forced expiratory volume in one second (FEV1). FEV1/FVC ratio, peak expiratory flow (PEF) and maximal expiratory flow at $25 \%, 50 \%$ and $75 \%$ of the FVC were all calculated.

All examinations were carried out according to the recommendations for the performance of spirometry (Stanojevic et al., 2008; Boros et al., 2004) with a portable spirometer (Pony-FX desk spirometer, Cosmed). Prior to the run and within 20 minutes after its completion, arterial oxygen saturation $\left(\mathrm{SaO}_{2}\right.$; Pulse Oximeter, ChoiceMMed) and blood pressure BP (semi-automatic blood pressure monitor M1 Compact, Omron) were measured, and heart rate was registered (HR; Sportester Polar FT1). 
Aural canal temperature $\left(T_{\text {ty }}\right)$ was measured with a ThermoScan, thermometer (Type 6201, BRAUN) at baseline $\left(T_{\text {tyo }}\right)$ and within 15 minutes after run completion $\left(T_{\text {ty }}\right)$. Body temperature was also taken of exposed body surfaces (ET) and covered body surfaces (CT) (RayTemp ${ }^{6}$ Infrared Thermometer, MERA). Based on pre- and post-run temperature and changes in heart rate $\left(H R_{0} v s\right.$. $\left.H R_{T}\right)$, the physiological strain index (PSI) was calculated using the following formula (Frank et al. 1996):

$$
P S I=5\left(T_{\text {tyT }}-T_{\text {tyo }}\right) \cdot\left(39.5-T_{\text {ty } 0}\right)^{-1}+5\left(H R_{T}-H R_{0}\right) \cdot\left(180-H R_{0}\right)^{-1} .
$$

The obtained data were subject to statistical analysis using Statistica Software version 10 (StatSoft Poland, 10.0). Descriptive statistics were used to summarize data and the significance of differences between the means was tested (Wilcoxon test). The results of the analyses were presented as means and standard deviations (means, SD). The significance level was set at $p<0.05$.

\section{Results}

Significant differences were found between female and male marathon runners regarding body height (172 \pm 3.5 vs. $184 \pm 3.8 \mathrm{~m} ; \mathrm{p}<0.01)$, body mass index $\left(19.9 \pm 1.5 \mathrm{vs} .21 .2 \pm 1.8 \mathrm{~kg} / \mathrm{m}^{2} ; p<0.05\right)$ and percent of body fat content (13.2 \pm 2.4 vs. $8.8 \pm 1.5 \%$; $p<0.01$ ). The mean marathon time was $3.48 \pm 0.35$ hours. A comparison of somatic parameters confirmed a significant post-marathon decrease in body weight and fat mass compared to premarathon values (Table 1).

Table 1. Anthropometric characteristics of the study subjects before and after marathon running

\begin{tabular}{lccc}
\hline \multicolumn{1}{c}{ Variables } & $\begin{array}{c}\text { Before marathon } \\
\mathrm{n}=23\end{array}$ & $\begin{array}{c}\text { After marathon } \\
\mathrm{n}=23\end{array}$ & $\begin{array}{c}\text { Statistical } \\
\text { significance }\end{array}$ \\
\hline Body mass $[\mathrm{kg}]$ & $68.7 \pm 11.3$ & $66.4 \pm 11.2$ & $\mathrm{P}<0.05$ \\
BMI $\left[\mathrm{kg} / \mathrm{m}^{2}\right]$ & $22.8 \pm 2.7$ & $22.3 \pm 2.6$ & $\mathrm{NS}$ \\
FFM $[\mathrm{kg}]$ & $57.9 \pm 10.5$ & $57.1 \pm 10.2$ & $\mathrm{NS}$ \\
FAT[\%] & $15.5 \pm 5.6$ & $14.5 \pm 5.5$ & $\mathrm{P}<0.01$ \\
FAT $[\mathrm{kg}]$ & $10.4 \pm 4.1$ & $9.6 \pm 3.9$ & $\mathrm{P}<0.01$ \\
TBW[kg] & $42.4 \pm 7.7$ & $41.9 \pm 7.5$ & $\mathrm{P}<0.05$ \\
\hline
\end{tabular}

BMI - body mass index; FFM - fat free mass; FAT \% - body fat percentage; FAT - fat mass; TBW - total body water.

High energy expenditure resulted in thermoregulatory changes manifested by a decrease in the temperature of covered (CT) $p<0.01$ and exposed body surfaces (ET) $p<0.05$ ); no significant differences were observed regarding aural canal temperature $\left(T_{\text {ty }}\right)$. The level of physiological strain index (PSI) was $2.2 \pm 0.7$. PSI reflects combined cardiovascular and thermoregulatory strain on a universal scale of 0 to 10 . Lower value and no significant PSI increase during a 15-minute post-marathon recovery period indicating good adaptation of the study participants to the marathon distance. Heart rate was higher and blood pressure (BPs and BPd) was significantly lower in 15 minutes recovery period compared baseline levels. There were no significant differences in $\mathrm{SaO}_{2}$ before and after marathon running (Table 2). 
Table 2. Temperature, blood pressure and heart rate before and after marathon running

\begin{tabular}{lccc}
\hline \multicolumn{1}{c}{ Varibles } & $\begin{array}{c}\text { Before marathon } \\
\mathrm{n}=23\end{array}$ & $\begin{array}{c}\text { After marathon } \\
\mathrm{n}=23\end{array}$ & $\begin{array}{c}\text { Statistical } \\
\text { significance }\end{array}$ \\
\hline $\mathrm{Tty}\left[{ }^{\circ} \mathrm{C}\right]$ & $36.07 \pm 0.4$ & $36.4 \pm 0.5$ & $\mathrm{NS}$ \\
$\mathrm{CT}\left[{ }^{\circ} \mathrm{C}\right]$ & $29.01 \pm 1.5$ & $26.6 \pm 3.1$ & $\mathrm{P}<0.01$ \\
$\mathrm{ET}\left[{ }^{\circ} \mathrm{C}\right]$ & $28.0 \pm 2.1$ & $27.0 \pm 2.3$ & $\mathrm{P}<0.05$ \\
$\mathrm{HR}[\mathrm{b} / \mathrm{min}]$. & $61.0 \pm 10.0$ & $94.0 \pm 18.0$ & $\mathrm{P}<0.01$ \\
$\mathrm{BP}_{\mathrm{S}}[\mathrm{mm} \mathrm{Hg}]$ & $135.0 \pm 15.7$ & $120.0 \pm 15.8$ & $\mathrm{P}<0.05$ \\
$\mathrm{BPd}[\mathrm{mm} \mathrm{Hg}]$ & $84.0 \pm 8.7$ & $77.1 \pm 15.2$ & $\mathrm{P}<0.05$ \\
$\mathrm{SaO}_{2}[\%]$ & $97.6 \pm 1.6$ & $98.2 \pm 1.6$ & $\mathrm{NS}$ \\
\hline
\end{tabular}

Tty - aural canal temperature; ET - temperature of exposed body surfaces; CT - temperature of covered body surfaces; $\mathrm{HR}$ - heart rate; $\mathrm{BPs}$ - systolic blood pressure; $\mathrm{BPd}$ - diastolic blood pressure; $\mathrm{SaO}_{2}$ - arterial oxygen saturation.

Compared to resting values, post-marathon spirometry revealed a significant decrease in post-marathon FVC (FVC\% 83.5 \pm 15.2 vs $73.4 \pm 22.3$; $p<0.05)$; forced expiratory volume in one second FEV1/FVC\% (91.5 \pm 5.0 vs 80.1 $\pm 18.1 ; p<0.05$ ) and peak expiratory flow (PEF $7.0 \pm 2.3$ vs $5.0 \pm 2.3 p<0.05$ ). Maximal expiratory flow (MEF $75 \%$ ) was significantly reduced; MEF50\% and MEF25\% also showed a decreasing tendency.

Table 3. Spirometry variables before and after marathon running

\begin{tabular}{|c|c|c|c|}
\hline Variables & $\begin{array}{l}\text { Before marathon } \\
\qquad n=23\end{array}$ & $\begin{array}{l}\text { After marathon } \\
\qquad n=23\end{array}$ & $\begin{array}{l}\text { Statistical } \\
\text { significance }\end{array}$ \\
\hline FVC [L] & $4.7 \pm 0.5$ & $3.64 \pm 0.8$ & $P<0.05$ \\
\hline FVC [\%pred] & $83.5 \pm 15.2$ & $73.4 \pm 22.3$ & $P<0.05$ \\
\hline FEV1 [L/s] & $18.8 \pm 2.9$ & $10.04 \pm 1.2$ & $P<0.05$ \\
\hline $\mathrm{FEV}_{1}[\%$ pred $]$ & $95.7 \pm 14.0$ & $79.4 \pm 10.0$ & $P<0.05$ \\
\hline $\mathrm{PEF}[\mathrm{L} / \mathrm{s}]$ & $7.0 \pm 2.3$ & $5.0 \pm 2.3$ & $P<0.05$ \\
\hline $\mathrm{FEF}_{(25-75)}[\mathrm{L} / \mathrm{s}]$ & $6.4 \pm 1.5$ & $4.7 \pm 1.7$ & $P<0.05$ \\
\hline $\mathrm{FEV}_{1} / \mathrm{FVC}[\%]$ & $91.5 \pm 5.0$ & $80.0 \pm 18.1$ & $P<0.05$ \\
\hline MEF75\% [L/min.] & $7.5 \pm 2.2$ & $4.9 \pm 1.8$ & $P<0.05$ \\
\hline MEF50\%[L/min.] & $5.5 \pm 1.3$ & $4.2 \pm 1.5$ & $P<0.05$ \\
\hline MEF25\%[L/min.] & $3.9 \pm 0.8$ & $2.9 \pm 1.3$ & $P<0.05$ \\
\hline
\end{tabular}

FVC - forced vital capacity; FEV1 - forced expiratory volume in one second; PEF - peak expiratory flow; $\mathrm{FEF}_{(25-75)}$ - mean forced expiratory flow at $25-75 \% \mathrm{FVC} ; \mathrm{FEV}_{1} / \mathrm{FVC}[\%]$ ratio; MEF $75 \%$ - maximal expiratory flow at $75 \%$ of the FVC; MEF $50 \%$ - maximal expiratory flow at $50 \%$ of the FVC; MEF $25 \%$ - maximal expiratory flow at $25 \%$ of the FVC.

\section{Discussion}

Breathing involves integrated actions of the respiratory and cardiovascular systems. Synchrony between the cardiovascular and respiratory systems allows regulation of pulmonary blood flow. Hence, gas exchange between the air within the alveoli and the pulmonary capillaries is maintained depending on the demand for oxygen by the cells in a tissue. The function of the respiratory system alters markedly during high-intensity endurance exercise (Dempsey et al., 2012; Stickland et al., 2004). These adaptive changes result in deepened respirations and more forced airflow through air passages. Efficient respiration is associated with an improvement in cardiovascular 
reserve capacity. This, in turn, helps increase oxygen uptake and carbon dioxide elimination according to the metabolic rate; constant levels of respiratory gases in the blood help maintain homeostasis (Green et al., 2012; Harms et al., 1997; Frank et al., 1998). The observed disturbances in physiological adaptation as well as the potential impact of environmental factors on oxygen pressure in alveolar air increase the risk of respiratory failure and may lead to serious health problems.

We evaluated lung function and adaptive changes in the respiratory and cardiovascular systems with respect to the physiological strain associated with long-distance running. FEV1, as well as forced and mean expiratory flow decreased after the run compared to resting values. Hypoxia and cardiovascular complications were not observed. The effort might have caused transient airflow obstruction in the respiratory tract; the diminished strength of the expiratory muscles might have resulted from respiratory muscle fatigue (Mahler, Loke, 1981).

Mahler, Loke, (1981) and Dempsey, Hanson, Henderson, (1984) also observed significant decreases in FVC, FEV1 and PEF after an ultramarathon and believed they resulted from impaired efficiency of the upper respiratory tract and respiratory muscle fatigue. Hypoxemia induced by lowered $\mathrm{SaO}_{2}$ also had a significant effect on aerobic efficiency of the long-distance runners.

In healthy individuals, pulmonary ventilation and pulmonary blood flow are subjects to dynamic changes; thus, the levels of respiratory gases in the blood remain constant, i.e., systemic arterial blood has an average oxygen tension $\left(\mathrm{PaO}_{2}\right)$ of approximately $95 \mathrm{~mm} \mathrm{Hg}$ while the partial alveolar pressure of $\mathrm{CO}_{2}\left(\mathrm{PACO}_{2}\right)$ is normally $40 \mathrm{mmHg}$. Impairments of respiratory homeostasis caused by, for example, hypoxia or hypercapnia, may have deleterious effects, and especially on metabolically active cells with highly oxidative metabolism including neurons of the central nervous system, heart and kidney cells (Vogiatzis et al., 2007; Dempsey et al., 2012; Roberts, Maron, 2005). Increased breathing rate promotes heat loss associated with evaporation of water from the alveoli and respiratory passages (Hölmich et al., 1988; Amann, 2012). It is important to note, that insufficient heat loss results in an increase in physiological strain including the thermoregulatory and cardiorespiratory system (Pilch et al., 2014). Physiological Strain Index (PSI) based upon heart rate and body temperature measurements, allowing the instantaneous assessment of overall physiological strain on a scale of $0-10$. Predictions of physiological strain may be important in determining physiological endurance and in protecting athletes against exercised induced thermal stressors (Moran et al., 1998; Pokora, Żebrowska, 2016). Physiological Strain Index calculated in our study reflects low cardiovascular strain (PSI $2.2 \pm 0.7$ ). Lower value and no significant PSI increase during a 15 -minute postmarathon recovery period indicating good adaptation of the study participants to the marathon distance. Despite differences in morphological characteristics and cardiac function there was only a slight effect on PSI. However, the contribution of the respiratory system differed significantly could potentially impair endurance performance and consequently impacting negatively on running economy.

Respiration during muscular work is known to be regulated by neural and humoral factors. Changes in hydrogen ion concentration, oxygen and carbon dioxide pressures affect respiration - either directly via central control of ventilation (chemosensitive areas, pre-Bötzinger complex) or indirectly, i.e., through activation of the chemoreceptor reflex. The activity in the pre-Bötzinger complex can be modified by impulses from metabolic receptors in the muscles. The receptors are activated through changes in chemical composition of the interstitial fluid in the muscles caused by increased energy metabolism during muscle contraction.

According to previous investigations, several factors might be responsible for disturbances in functional adaptation of the respiratory system to long-lasting physical effort, and among them: 1) contraction of the bronchial 
smooth muscle and increased resistance of the respiratory tract to airflow resulting in decreased blood flow into the left atrium and cardiac output, 2) constriction of the upper respiratory tract, decreased pressure gradient in the pulmonary capillaries and resultant tissue hypoxia, 3) fatigue of the respiratory muscles, primarily the diaphragm, resulting in reflex-mediated contraction of peripheral vasculature and hence decreased arterial blood flow to lower limbs (Vogiatzis et al., 2007; Busotti et al., 2014; Eldridge et al., 2004). Paradoxically, it has been shown that individuals achieving better results in sport are more susceptible to respiratory failure and upper respiratory tract infections (Peters, Bateman, 1983).

In summary, it should be emphasized that long-distance running results in functional changes within the respiratory system which may limit the adaptive potential and decrease exercise tolerance.

\section{References}

Amann, M. (2012). Pulmonary system limitations to endurance exercise performance in humans. Experimental Physiology, 97 (3), 311-318.

Boros, P., Franczuk, M., Wesołowski, S. (2004). Zasady interpretacji wyników badania spirometrycznego. Pneumologia Alergologia Polska, 72, 20.

Bussotti, M., Di Marco, S., Marchese, G. (2014). Respiratory disorders in endurance athletes-how much do they really have to endure? Journal of Sports Medicine, 5, 47-63.

Dempsey, J.A., Amann, M., Harms, C.A., Wetter, T. (2012). Respitarory system limitations to performance in the healthy athletes: some answers, more questions! Deutsche Zeitschrift für Sportmedizin, 63 (6), 157-162.

Dempsey, J.A., Hanson, P.G., Henderson, K.S. (1984). Exercise-induced arterial hypoxaemia in healthy human subjects at sea level. Journal of Physiology, 355, 161-175.

Eldridge, M.W., Dempsey, J.A., Havercamp, H.C., Lovering, A.T., Hokanson, J.S. (2004). Exercise induced intrapulmonary arteriovenous shunting in healthy humans. Journal of Applied Physiology, 97, 797-805.

Frank, A., Moran, D., Epstein, Y., Belokopytov, M., Shapiro, Y. (1996). The estimation of heat tolerance by a new cumulative heat strain index. In: Y. Shapiro, D. Moran, Y. Epstein (eds.), Environment Ergonomics: Recent Progress and New Frontiers (pp. 194-197) London: Freund.

Green, D.J., Spence, A., Rowley, N., Thijssen, D. H., Naylor, L.H. (2012). Vascular adaptation in athletes: is there an 'athlete's artery? Experimental Physiology, 97, 295-304.

Harms, C.A., Babcock, M.A., McClaren, S.R., Pegelow, D.F., Nickele, G.A., Nelson, W.B., Dempsey, J.A. (1997). Respiratory muscle work compromise leg blood flow during maximal exercise. Journal of Applied Physiology, 82, 1573-1583.

Hölmich, P., Darre, E., Jahnsen, F., Hartvig-Jansen, T. (1988). The elite marathon runner: Problems during and after competition. British Journal of Sports Medicine, 22 (1), 19-21.

Hopkins, S.R., Gavin, T.P., Siafakas, N.M., Haseler, L.J., Olfert, I.M., Wagner, H., Wagner, P.D. (1998). Effect of prolonged, heavy exercise on pulmonary gas exchange in athletes. J Appl Physiol., 85: 1523-1532.

Kalliokoski, K.K., Laaksonen, M.S., Luotolahti, M., Laine, H., Takala, T.O., Nuutila, P., Knuuti, J. (2004). Myocardial perfusion after marathon running. Scandinavian Journal of Medicine \& Science in Sports, 14, 208-214.

Kruk, J. Good scientific practice and ethical principles in scientific research and higher education. (2013). Central European Journal of Sport Sciences and Medicine, 1, 25-29.

Mahler, D.A., Loke, J. (1981). Lung function after marathon running at warm and cold ambient temperatures. American Review of Respiratory Disease, 124, 154-157.

Moran, D.S., Shitzer, A., Pandolf, K.B. (1998). A physiological strain index to evaluate heat stress. American Journal of Physiology, $275,129-134$.

Neilan, T.G., Yoerger, D.M., Douglas, P.S., Marshall, J.E., Halpern, E.F., Lawlor, D., Picard, M.H., Wood, M.J. (2006). Persistent and reversible cardiac dysfunction among amateur marathon runners. European Heart Journal, 27, 1079-1084.

Peters, E., Bateman, E.D. (1983). Ultramarathon running and upper respiratory tract infections. An epidemiological survey. South African Medical Journal, 64, 582-584. 
Pilch, W., Szyguła, Z., Palka, T., Pilch, P., Cison, T., Wiecha, Sz., Tota, Ł. (2014). Comparison of physiological reactions and physiological strain in healthy men under heat stress in dry and steam heat saunas. Biology of Sport, 31 (2), 145-149.

Pokora, I., Żebrowska, A. (2016). Application of A Physiological Strain Index in Evaluating Responses to Exercise Stress-A Comparison Between Endurance and High Intensity Intermittent Trained Athletes. Journal of Human Kinetics, 50 (1), 103-114.

Predel, H.J. (2014). Marathon run: cardiovascular adaptation and cardiovascular risk. European Heart Journal, 35, 3091-3096.

Roberts, W.O, Maron, B.J. (2005). Evidence for decreasing occurrence of sudden cardiac death associated with the marathon. Journal of American College of Cardiology, 46, 1373-1374.

Stanojevic, S., Wade, A., Stocks, J., Hankinson, J., Coates, A.L., Pan, H., Rosenthal, M,. Corey, M,. Lebecque, P,. Cole, T.J. (2008). References ranges for spirometry across all ages: a new approach. American Journal of Respiratory Critical Care Medicine, 177 (3), 253-260.

Stickland, M.K., Welsh, R.C., Haykowsky, M.J., Petersen, S.R., Anderson, W.D., Taylor, D.A., Bouffard, M., Jones, R.L. (2004). Intrapulmonary shunt and pulmonary gas Exchange during exercise in humans. Journal of Physiology, 561, 321-329.

Vogiatzis, I., Georgiadou, O., Koskolou, M., Athanasopoulos, D, Kostikas, K., Golemati, S., Wagner, H., Roussos, C., Wagner, P.D., Zakynthinos, S. (2007). Effects of hypoxia on diaphragmatic fatigue in highly trained athletes. Journal of Physiology,15 (581), 299-308.

Zilinski, J.L., Contursi, M.E., Isaac, S.K., Deluce, J.R., Lewis, G.D., Weiner, RB., Hutter, A.M., d'Hemecourt, P.A., Troyanos, C., Dyer, K.S., Baggish, A.L. (2015). Myocardial adaptations to recreational marathon training among middle-aged men. Circulation Cardiovascular Imaging, 8 (2), e002487.

Cite this article aS: Przybyła, K., Żebrowska, A., Posmysz, A., Manowska, B., Pokora, I., Żak, A. (2016). Long-distance Running and its Effects on Cardiorespiratory Adaptation and Physiological Strain in Marathon Runners. Central European Journal of Sport Sciences and Medicine, 13 (1), 81-87. DOI: 10.18276/cej.2016.1-08. 
